\title{
Psychophysiologic features and personal-adaptive potential of students with limited abilities
}

\author{
Elena N. Kalenik1, Valentina B. Salakhova ${ }^{1}$, Mikhail N. Mikhaylovsky², Marina E. Zhelezniakova ${ }^{3}$, Alexander V. Bulgakov ${ }^{4}$ \\ Aleksey A. Oshchepkov ${ }^{5}$
}

\begin{abstract}
Objective: The article contains the results of studying homeostasis of the cardiovascular system by the method of cardiointervalography in students with limited abilities of various programs of study at university. A psychological assessment of the attitude of students with limited abilities to their health was made. The problem of the components of the personal-adaptive potential has been studied. A study of the level of human potential of students on a separate component of "health" and in the aggregate has been conducted, as well as conclusions based on this research work have been drawn.

Method: To solve the objectives set in the study, the following methods were used: the review of scientific and methodological literature, instrumental and calculated physiological research methods: variational pulsometry; mathematical analysis of the heart rate variability; calculation method for assessing adaptive capacity - adaptive capacity offered by Bayevsky; the questionnaire "Psychological features of a person's attitude to his health", in the framework of a study of the human potential index (health component), a questionnaire was developed based on a questionnaire for assessing the quality of life, developed at the Institute of Stress Medicine (USA) in 1993, methods - descriptive mathematical statistics and testing the hypothesis by Student's t-test.

Results: The analysis of the activity index of the sympathic regulation link - mode amplitude (AMo\%) according to the standards of homeostasis, in view of variation pulsograms, is characterized in the studied groups, as moderate sympathicotonia. The AMo index in the groups is not statistically different, reflects the stabilizing effect of centralization of the heart rate control, and indicates the activation of the sympathic division of the autonomic nervous system (ANS). AMo 1 year $=40.8 \pm 8.1 \%$; AMo 2 year $=44.9 \pm 4.8 \%$; AMo 3 year $=43.9 \pm 8.8 \%$ the index is in the upper limits of the norm, the index is normal only in the group of first year students. It can be stated that the body of students with limited abilities reacts with a nonspecific adaptive response to the study load, and this depends on the specifics of the diseases and functional reserves that are low in this category of students. The indicator of urgent adaptation - vagosympathetic balance (LF / HF) shows the greatest stress in the group of first-year students. The index is statistically reliably different from the LF / HF1 year $=2.074 \pm 0.39$ * (according to the paired Student's t-criterion of dependent indices $p \leq 0.5$ ) from that of students in the second LF / HF2 year $=1.174 \pm 0.25$ and the third LF / HF3 year $=1.308 \pm 0.26$ years of study, indicating an increase in sympathic influences. A decrease in the ratio of the LF / HF index in the groups of second and third year students can be interpreted as a positive effect. There was general adaptation to the educational process at the university, and the correct construction of training and health-related workloads, in accordance with the medical diagnosis, led to a balanced regulation of the sympathic and parasympathic nervous system.

Conclusion: The stress level of regulatory systems is assessed by the value of the adaptation potential. The higher is the adaptive capacity of the circulatory system, the lower the values of the adaptive potential. The adaptive potential is an indicator that determines the interrelation of two opposite concepts: "health" and "disease", morpho-functional changes. In case of illness, a shift towards disadaptation takes place.
\end{abstract}

Keywords: personal-adaptive potential, students with limited abilities, psychological assessment of attitude to health, heart rate analysis, stress index

\section{INTRODUCTION}

Human capital is one of the most valuable resources for society. In recent years, the general opinion has been that the effectiveness of the economy development of many contemporary states to a great extent depends on how much money the state invests in its citizens. To measure the standard of living, literacy, education, and longevity as the main characteristics of human potential, we have introduced such indicator as the IHD (Index of Human Development). This indicator has been published in the framework of the United Nations Development Program in the annual reports on

\footnotetext{
1 Ulyanovsk State University, Ulyanovsk, Russia.

2 Sechenov First Moscow State Medical University, Moscow, Russia

3 State Social and Humanitarian University, Kolomna, Russia.

4 Russian State Humanitarian University, Moscow, Russia.

5 National Research Nuclear University (Branch), Dimitrovgrad, Russia.
}

Correspondence: Valentina B. Salakhova

Ulyanovsk State University, Ulyanovsk, Russia.

E-mail: valentina_nauka@mail.ru

Received: 10 Aug 2018, Accepted: 22 Oct 2018

(C) 2018 by the authors; licensee Modestum Ltd., UK. This article is an open access article distributed under the terms and conditions of the Creative Commons Attribution License (http://creativecommons.org/licenses/by/4.0/). 
human development since 1990. Referring to the "Human Development Report in the Russian Federation for 2017", we found that Russia with an index of 0.804 for the first time in 2015 was among the countries with a high level of human development (Norway leads with an index of 0.949 in 2015). The world average index was 0.717 , which is significantly lower than in Russia. Having given the value of the IHD for Russia at the level of 0.805 , that is, according to the data of the 2016 report, the index in Russia in 2015 decreased slightly due to a decrease in GDP at PPP (purchasing power parity) (1).

The current stage of economic development determines the importance of considering human capital as a holistic reflection of human resources and the foundation for allocating and functioning intellectual, social and cultural capital, since this is what contributes to the recognition of the need to invest in the full development of human potential.

Human capital is the most important (but not the only) form of the human potential manifestation. We stick to the position that the definition of human potential is an integral part of the concept of human capital, since in both cases an individual with a certain education, a state of health, upbringing and motivation is considered, but the concept of human capital relates more to economic activity, while human potential is closer to sociological and psychological concept (2 -11).

Health remains the most important value, and its integral index is the end result of a person's effective functioning. The state of health of students is one of the most important generalizing parameters of a nation's health (1).

From the point of view of the medical aspect: social health is a characteristic of the physical and mental health of society, i.e. health of society (12).

The shift from psychological health to the social level is very conditional. However, in the second case, a person is thought of as a social being, and here the most important issues are the impact on the health of the individual, as well as the fulfillment of social functions by the person. This fact is of great importance for students with disabilities. Social health is determined by the quantity and quality of the interpersonal relationships of the individual and the degree of his participation in the life of society. Disorders in the field of social health may be due to the dominance of certain personal characteristics (conflict, self-centeredness, etc.). In addition, according to a number of authors (13) these properties determine the process of the deviant behavior formation. They can be divided into external factors and internal development processes leading to the personality deformation.

The problem of social health of students with disabilities under modern conditions is starting to assume a mobile character. "Social changes can turn a previously formed socialization into unsuccessful one, and the opportunity to achieve success in this regard also depends on the ability to adapt under changed conditions" (14-19).

The person himself plays a decisive role in maintaining and saving his own health. This is connected with his ability to assess the state of his health. At the same time, the effectiveness of self-assessment of health directly depends on understanding oneself.

The attitude to health is a system of individual, selective connections of a personality with various phenomena of the surrounding reality, contributing to or, on the contrary, threatening the health of people, as well as a definite assessment by an individual of his social health, physical and mental state $(19,20)$.

The need for health has a potential value that is actualized in a state of illness, and, secondly, a value that varies in meaning. Its importance especially increases for students with disabilities (HIA) under conditions of an accelerated pace of life, an increase in the volume of educational information, and a complication of the learning process in higher education.

Thus, we took interest in determining the psychological characteristics of the attitude of students with disabilities to their health, to study the influence of training at the university on their functional state, and to trace changes in the indicator (health component) of human potential among students $(7,21-25)$.

\section{MATERIALS AND METHODS}

To solve the problems posed in the course of the study, the following methods were used: the analysis of the scientific and methodological literature, instrumental and calculated physiological research methods: variational pulsometry; mathematical analysis of the heart rate variability; the calculation method for assessing adaptive capacity - adaptive capacity offered by Bayevsky; psychological studies - a questionnaire "Psychological features of a person's attitude to his health", in the framework of a study of the human potential index (health component), a questionnaire was developed on the basis of a questionnaire to assess the quality of life, developed at the Institute of Stress Medicine (USA) in 1993 (25), the methods - descriptive mathematical statistics and testing the hypothesis using Student's t-criterion. 


\section{Experimental Part}

The study was conducted in the physiological laboratory of the Faculty of Physical Education, Institute of Medicine, Ecology and Physical Education, Ulyanovsk State University. The study involved students with disabilities of Ulyanovsk State University from the first to the third year of full-time study of various programs, the total number of 30 young people. The subjects were divided into three groups ( $n-10)$ : group 1 - 1 year, group 2 - 2 year, group 3 - 3 year.

In these groups the students were distributed according to their diseases in the following way:

Group $1-50 \%$ diseases of the loco-motor system (with outcomes of complex fractures, spinal surgery, arthritis, etc.) $30 \%$ diseases related to endocrinology and nephrology, $20 \%$ of students with diseases of the cardiovascular system.

Group 2 - 60\% of students with diseases of the cardiovascular system, 10\% - diseases related to the clinic of nervous diseases (epilepsy), 10\% - with chronic nonspecific lung diseases, 20\% - diseases of the loco-motor system.

Group 3 - 10\% of students with diseases of the loc-motor system, 20\% of diseases related to nephrology, $30 \%$ of students with diseases of the cardiovascular system, $10 \%$ with chronic nonspecific lung diseases, $30 \%$ diseases of the digestive system.

Each group was examined with the use of the computer technology and "a complex for processing cardiointervalograms and analysis of the heart rate variability Varicard 2.51".

Each group was examined using the computer program Varicard 2.51.

Cardiointervalography by Bayevsky (heart rate variability - HRV) is recognized by the Western scientific community as the only means of integrated assessment of the sympathic and parasympathic activity of the ANS. Although one of the leading vegetologists (Wayne) draws attention to the fact that its indicators testify only to the "homeostasis of the cardiovascular system" and very relatively to the general vegetative tone. In addition, developers think of homeostasis as the dynamic balance between environmental conditions and physiological functions of the body, in which each physiological system at the same time provides its own stability and adaptation to new needs (23). It was important for us to trace the adaptation and adaptive capacity of the body of a student with disabilities to university studies, and the cardiointervalography method can provide an objective assessment and result in terms of the objectives set in the study.

\section{RESULTS AND DISCUSSION}

After conducting a statistical and autocorrelation analysis of the heart rate, we found that the heart rate indices are gradually increased in all groups, relative to age. The heart rate indices in groups 1 and 3 are in the upper limits of the norm (HR1 year $=86 \pm 5.3$ beats $/ \mathrm{min}$; HR3 year $=88.9 \pm 5.2$ units / $\mathrm{min}$ ). The students of the 2 year HR2 $=109.6 \pm 9.1$ beats / min. above normal. By paired Student t-test of dependent indices $(p \leq 0.5)$, HR2 year is statistically different than in the other two groups. Perhaps this is due to the specificity of the disease, $60 \%$ of the $2^{\text {nd }}$ year students have a history of cardiovascular diseases. We also believe that the 2 nd year students react to the educational process with a nonspecific adaptive response. We can support this conclusion with the following results of our research.

A "stress index" $\mathrm{SI}$ ) of the first year students has a functional norm on average, while in the other two studied groups the regulatory systems of the body have moderate sympathicotomy (autonomic tone SI 1 year $=142.5 \pm 48.8$; SI 2 year $=198.5 \pm 48$, 9; SI 3 year = $171.6 \pm 76.7$ ). In the second group, the "SI" has an upper limit of moderate sympathicotomy, which indicates a more pronounced stress state of second-year students. This index is extremely sensitive to an increase in the tone of the sympathetic nervous system. The organism reacts to such "excitation" as studying at the university for students with disabilities "by mobilizing functional reserve mechanisms that smooth out and compensate for possible disturbances of homeostasis" (27).

In our work, we obtained data that reflect a psycho-emotional stress. The mobilization of energy and metabolic reserves during functional effects may be reflected by changes in the power of the spectrum in the VLF range. Despite the conditional and in many ways still controversial nature of this interpretation of changes in VLF, it can be useful in studies of both healthy people and patients with various conditions associated with impaired metabolic and energy processes in the body. The VLF index in the studied groups is in the range of $18.4 \pm 4.5 \%, 17.9 \pm 5.9 \%, 18.9 \pm 6.0 \%$ of low values (in the first, second and third research groups, respectively), which corresponds to VLF "below the norm". Changes in the index do not differ significantly in groups, and the values are slightly below the norm, but this result can be interpreted as a lack of body reserves, the effect of the disease. The psycho-emotional burden on students with disabilities in higher education institutions is complex, during training students with health impairments develop their inherent abilities and organize their behavior, resulting in the formation of motivational, psychosomatic and somatic aspects that distinguish them from other students. In scientific papers there are studies confirming this fact (28). 
The quantitative characteristic of the relationship between the central and autonomous circuits of the heart rate regulation, the IC (index of centralization), in the studied groups is within the normal range and is not statistically different (IC1 year $=2.88 \pm 0.51$; IC 2 year $=2.21 \pm 0.87$; IC 3 year $=2.11 \pm 0.46)$. However, the indicator is within the lowest values, as evidenced by the somatic aspect of students with disabilities.

We considered the results by the method of "manual" mathematical analysis of the heart rate variability according to Bayevsky in the following mathematical indicator - AMo (mode amplitude). The amplitude of the mode (AMO) is the number of cardiointervals, corresponding to the value of $\mathrm{Mo}$, as a percentage of the sample size. The mode (Mo) is the value of the cardiointerval, most often found in the dynamic range. This is the most reliable level of functioning of the cardiovascular system. With a normal distribution and high stationarity of the process under study, Mo differs little from the mathematical expectation. It displays the stabilizing effect of controlling the heart rate, which is caused by the activation of the sympathic part of the ANS.

The analysis of the activity of the sympathic regulation link - mode amplitude (AMo\%) according to homeostasis standards, according to variation pulsograms offered by R.M. Baevsky (26), is characterized in the studied groups, as moderate sympathicotonia. The AMo index in the groups is not statistically different, reflects the stabilizing effect of centralization of the heart rate control, and indicates the activation of the sympathic division of the autonomic nervous system (ANS). AMo1 year $=40.8 \pm 8.1 \%$; AMo 2 year $=44.9 \pm 4.8 \%$; AMo 3 year $=43.9 \pm 8.8 \%$ index is in the upper limits of the norm, the index is normal only in the group of the 1 year students. It can be stated that the body of students with disabilities reacts with a nonspecific adaptive response to the study load, and this depends on the specifics of the diseases and functional reserves that are low in this category of students.

The indicator of urgent adaptation - vagosympathic balance (LF / HF) shows the greatest stress in the group of firstyear students. This index statistically reliably differs from the LF / HF1 year $=2.074 \pm 0.39$ * (according to the paired Student's t-criterion of dependent indices $p \leq 0.5)$ from that of the students of the second LF / HF2 year $=1.174 \pm 0.25$ and the third LF / HF3 year $=1.308 \pm 0.26$ years of study, which indicates an increase in sympathic influences. A decrease in the ratio of the LF / HF index in the second and third year groups can be interpreted as a positive effect. There was a general adaptation to the educational process at the university, and the correct construction of training and healthrelated workloads, in accordance with the medical diagnosis, led to a balanced regulation of the sympathic and parasympathic nervous system. This fact is consistent with the results of the work conducted by R.S. Minvaleyev, A.I. Ivanova, V.A. Vishnevsky, S.I. Loginov, A.Sh. Bektimirov, E.N. Lopatnikova, A.A. Fedyakina, N.A. Semyonova, Zh.G. Kortava, and others, where was shown that after the proper execution of loads, an increase in the tone of the parasympathic division of the autonomic nervous system leads to a balanced regulation (29). Although other indicators prove that there is a difficult process of adaptation and not always a positive balance of regulation among students with disabilities, and especially among second-year students.

The tension level of regulatory systems is assessed according to the magnitude of the adaptive potential. The higher the adaptive capacity of the circulatory system is, the lower the values of the adaptive potential. The adaptive potential is an indicator that determines the interrelation of two opposite concepts: "health" and "disease". As one of the criteria for assessing adaptation abilities, the assessment of the adaptive potential according to Bayevsky was proposed for students (29).

At the time of the study in groups, among students, the assessment of the adaptation potential (AP) according to Bayevsky (29) corresponded to a normal (satisfactory) adaptation in the first and third years AP1 year $=2.05 \pm 0.03$ and AP 3 year $=2.04 \pm 0.04$, respectively. In the group of second year students, the values were slightly worse and corresponded to the stresses of the adaptation mechanisms of AP 2 year $=2.1 \pm 0.07$. We believe that it is more difficult for 2 nd year students to adapt to the university environment. There is a greater number of special subjects in the curriculum of 2 nd year students, the volume of hours in the subjects of the general - humanities course decreases. Due to the complexity of mastering special subjects, theoretical and practical training, leading to a greater burden for students with disabilities, morpho-functional changes take place. A shift towards disadaptation takes place in case of illness. This indicator is confirmed by the following psychological research.

A healthy person should be as adaptable as possible to the environment. Assessing the health status with the use of the "Express - health assessment" the overall assessment represents a low level of health in all the groups, both among girls and boys.

1. To interpret the answers to the question "What is health?", The content analysis procedure was used: 
- when analyzing the definitions of the concept "health" obtained in the study of a group of subjects, the essential signs of health were considered as semantic units of content, as well as the frequency of their occurrence was determined: (\% of the total number of respondents).

Thus, the most frequent characteristics of health, reflecting the individual characteristics of students' attitudes toward their health, were the following:

1. The majority of respondents $(40.6 \%)$ define health as a state characterized by well-being (feeling of comfort, wellbeing, serenity).

2. Health is characterized as the absence of painful sensations or diseases (approximately $21.8 \%$ of respondents express this opinion, for example, stating that "Health is the absence of diseases" or "Health is when nothing hurts").

3. $15.6 \%$ of respondents consider the harmonious combination of spiritual and physical principles in a person an important characteristic of health (for example, "Health is physical, mental, social and spiritual well-being").

4. Health is also regarded as a required condition to achieve success in various fields of activity (for example, $15 \%$ of respondents defined health as "the opportunity to be active and live comfortably").

On the basis of the study results of the psychological characteristics of the attitude to their health, students of all years have a high degree of adequacy at the value-motivational level. In the hierarchy of values, students are motivated to preserve and improve health. Thus, the attitude of students to their health, on the one hand, reflects the experience of the individual, and on the other, has a significant impact on his behavior. Students act adequately by the degree of compliance of actions and deeds with the requirements of a healthy lifestyle.

However, the assessment of the behavioral scale of the 2 nd year students is lower than that of the freshmen and senior students. It means that $2^{\text {nd }}$ year students understand that they do little to take actions aimed at preserving their health.

At the cognitive level, students have the following assessment: $1^{\text {st }}$ year $=64 \pm 4.1$ p., $2^{\text {nd }}$ year $=75.9 \pm 5.3$ p., $3^{\text {rd }}$ year $=74.2 \pm 5.7 \mathrm{p}$. First-year students have a lower grade than in the other two groups and indicate: a low degree of awareness and competence in the field of health. They believe that they have little knowledge of the main risk factors and anti-risk in understanding the role of health in ensuring an active and long life.

At the emotional level, the indicator of anxiety in relation to one's health is inadequate in all groups. Because of their limited abilities, students do not know how to "enjoy the state of health and be happy with it." Correcting unfavorable aspects, the adaptation to study at the university, taking account of the disease, is a long and sometimes very painful process for the student's personality, combined with overcoming internal conflicts and negative emotional experiences (30). The reason for this discrepancy, apparently, is that very often people perceive health as something unconditionally given or taken for granted, the need for which, although realized, is felt only in the context of deficiency, which is clearly expressed in students with impaired health.

\section{CONCLUSION}

Discussing the changes of the human potential index in students studying at USU, in the component "health" we found that - the average index of the health potential in the first year students reaches 17.6 points - "average". Comparing the data of the first stage and the second in dynamics, we obtained the following data: - the average index of the health potential in the group of second year students reached 19.5 points, and we see an increase in comparison with the group of first year students (17.6 b.), - the average index of the potential health among third year students reached 20.4 points;

Summarizing the results of the study, we observe that the index of human potential of USU students during the period of study fluctuated slightly, but, nevertheless, it maintained its position at an average level. This is indicative of the stability of the studied index in the formed focus group. However, in the questionnaires about their human capital, students admitted low potential: "one's own physical development seems to be extremely low. There are practically no elements of special education in this area, and the respondent is far from his physical perfection. Motivation and value orientations are sometimes directed away from those that a healthy lifestyle implies. The origins of this state of poor physical culture should be sought from the time of studying at school, when, for health reasons, the respondent was 
released from PT classes. In this regard, there was a certain alienation from physical culture, and in fact the need for it was eliminated." A student of the 2 year.

Thus, the targeted formation of the correct attitude to health is of particular importance for students with limited abilities. A special role is given to physical training classes, the creation of cognitive conditions for the acquisition of knowledge and skills that would contribute to the prevention of diseases caused by pathological changes in the body.

\section{ACKNOWLEDGEMENTS}

The publication was prepared in the framework of the project supported by the Grant President, order number MK1562.2018.6

\section{REFERENCES}

1. Zobov RA, Kozlov AA. Actual problems of social health research. St. Petersburg: Himizdat. 2004.

2. Berezovskaya RA., Nikiforov GS. Attitude to health. Psychology of health. St. Petersburg: Himizdat. 2003.

3. Bubnov YuA, Endovitsky DA, Bubnov YuA, Gaidar KM. Actual problems of education of youth in modern Russia. In Bulletin of Voronezh State University. 2017;2:5-11.

4. Enyashina NG, Gridneva SV, Khudyakova TL, Gridyaeva LN, Pozharskay EL, Deberdeeva NA. Development of Higher Education Students' Creative Abilities in Learning and Research. In Eurasian Journal of Analytical Chemistry. 2017;5b:753-763.

5. Fedyakin AA, Semenov ON, Kortava ZHG. Adaptive changes in the activities of the cardiovascular system of women in the process of training in school health. In Scientific and theoretical journal "Uchenye zapiski". 2010;7(65):82-86.

6. Kalinina NV, Kalinin IV. Social adaptation of school children in an inclusive school: resources and opportunities. Society: Sociology, Psychology, Pedagogy. 2016;5:34-36.

7. Kassil GN, Weisfeld IL, Metlina EL, Schreiberg. Humoral and hormonal mechanisms of regulation of functions in sports activities. Moscow: Science. 1978.

8. Lipatova NV, Salakhova VB, Chertushkina TA, Ermolayeva SV, Mikhaylova IV, Shrol OY, Panteleev SV. An adaptive man: hardiness resources in the conditions of system crises at the turn of the xix-xx and the $\mathrm{xx}-\mathrm{xxi}$ centuries. Mediterranean Journal of Social Sciences. 2015;6(2)S3:136-141.

9. Masalimova AR, Shaidullina AR. Diversification of Professional On-the-Job Training Models and Forms in Contemporary Business Conditions. In Modern Journal of Language Teaching Methods. 2017;7(3):554-561.

10. Mitin SN. System-synergetic approach as a basis of work of the expert working with youth. In Simbirsk Scientific Bulletin. 2014;3(17);44-49.

11. Ovsyanik OA, Belinskaya DB, Kochetkov IG, Deberdeeva NA. 'Specific Features of Value Orientations and Social Mindsets of Deviant Teenagers'. In International journal of environmental \& science education. 2016;11(18):12327-12336.

12. Kalenik EN, Kashirin VA, Konovalova LV. The impact of university studies on the health status of students with disabilities of different courses. Adaptive physical education. 2016;3(67):15-22.

13. Vygotsky LS. Psychology. Moscow: April Press: EKSMO-Press. 2000.

14. Mitin SN. Psychotherapeutic approach in the management of the development of educational systems. Simbirsk Scientific Bulletin. 2016;4(26):31-39.

15. Mitin SN, Belinskaya DB, Vasyakin BS, Kamneva EV, Lipatova NV. A socionomic approach in studying key types of the personality's viability. Modern Journal of Language Teaching Methods. 2017;5:18-28.

16. Salakhov WB. The problem of resocializing a deviant personality. Simbirsk Scientific Herald. 2015;3(21):134-157.

17. Salakhova VB, Ovsyanik OA, Shmeleva NB, Lvova EN, Shabanova OV. The Problem of Higher Education in the Executive System of Russian Government. InternationalJournal of Environmental \& Science Education. 2016;11(4):9883-9889.

18. Salakhova VB, Tashcheva Al, Gridneva SV, Zhmurin IE, Mikhaylovsky MN. Experimental study of social and psychological correction of the teenage peronality's values and motivation sphere who is prone to deviant behavior. Modern Journal of Language Teaching Methods (MJLTM). 2017;7(4):12-20.

19. Volkova AyU, Kalenik EN. Human potential of modern youth on the example of a group of students of UISU. Simbirsk Scientific Herald. 2018;2(32):42-46 
20. Masalimova AR, Schepkina NK, Leifa AV, Shaidullina AR, Burdukovskaya EA. Mentoring perfection in modern enterprises conditions: practical recommendations. American Journal of Applied Sciences. 2014;11(7):1152-1156. https://doi.org/10.3844/ajassp.2014.1152.1156

21. Bubnov YuA. Philosophical and methodological foundations of health-saving education. Problems of the health of students and students. New scientific trends in medicine and pharmacy. Voronezh: Voronezh State University; 2008.

22. Derffel K. Statistics in analytical chemistry. Moscow: World. 1994.

23. Dronova TA, Dronov AA. Tolerance from the position of value attitude to man. In Scientific and theoretical journal of the Russian Academy of Education. 2017;3:33-37.

24. Efimova OI, Oshchepkov AA, Chirkovskaya EG, Klepach YV, Gridyaeva LN. The Experience of Studying Specific Features of Social Attitudes and Value Orientations among Normative and Deviant Teenagers. In Eurasian Journal of Analytical Chemistry. 2017;7b(12):1549-1553.

25. Gnedova SB, Emelyanenkova AV, Mikhailova IV, Sedunova AS, Enyashina NG, Salakhova VB. Individual Characteristics of Students in the Course of Professional Development (as Exemplified by the Ulyanovsk Region of Russia). In Asian Social Science. 2015;11(3):168-176.

26. Convention on the Rights of Persons with Disabilities. Retrieved from http://www.un.org/en/documents/decl_conv/conventions/disability.shtml

27. Bubnov YuA. Heuristic educational environment in a historical retrospective. Philosophical and psychologicalpedagogical problems of the development of the educational environment in modern conditions. Voronezh: IPC Voronezh State University. 2010.

28. Efimova OI, Salakhova VB, Mikhaylova IV, Gnedova SB, Chertushkina TA, Agadzhanova ER. Theoretical review of scientific approaches to understanding crisis psychology. Mediterranean Journal of Social Sciences. 2015;2:3-11.

29. Kalinina NV, Kalinin IV, Salakhova VB, Oschepkov AA, Simanovskaja MA. The Use of Social Resources of Inclusive Educational Environment to Cope Difficult Situations by Adolescents. IEJME-Mathematics Education. 2016;11(7):2527-2536.

30. Masalimova AR, Chibakov AS. Experimental analytical model of conditions and quality control of vocational training of workers and specialists. Mathematics Education. 2016;11(6):1796-1808.

$\diamond \diamond \diamond \diamond \diamond \diamond \diamond$

http://www.ejgm.co.uk 